\title{
Un importante avance
}

\author{
La Editorial del Politécnico Grancolombiano fue acreditada por Colciencias \\ para la publicación de libros resultado de investigaciones
}

El 1 de junio de 2012 el Departamento Administrativo de Ciencia, Tecnología e Innovación de Colciencias realizó una Convocatoria Abierta invitando a las Editoriales interesadas a participar en el Proceso de Registro de Editoriales Nacionales.

La convocatoria indica que desde 1991, Colciencias ha liderado el proceso de Medición de Grupos de Investigación del país, que responde a la política de apoyo al fortalecimiento y consolidación de los mismos.

Establece como propósito de la Convocatoria" "Reconocer y fomentar las prácticas de las organizaciones editoriales que garantizan la calidad científica, académica y editorial de los libros producidos, en particular de aquellos libros y capítulos de libro considerados resultados de investigación."

Dentro de los objetivos específicos estableció:
- "Fortalecer el Modelo de Medición de Grupos de Investigación mediante la aplicación de una herramienta para la validación del producto Libro Resultado de Investigación".

- "Implementar un mecanismo confiable y ágil para el reconocimiento y validación de los libros que constituyen un medio para la difusión y apropiación del conocimiento generado por la investigación nacional".

- "Identificar y fomentar las capacidades de gestión específicas en las organizaciones editoriales que les permiten reconocer, gestionar y validar los libros resultados de investigación."

- "Desarrollar procesos de retroalimentación que acerquen a las organizaciones editoriales nacionales a implementar prácticas editoriales de calidad científica".

1 http://www.colciencias.gov.co/convocatoria/convocatoria-abierta-mediante-la-cualse-invita-las-editoriales-interesadas-en-particip

2 Idem. 
En el Politécnico Grancolombiano hemos contado con una Editorial dinámica, nacida de la necesidad de fomentar la producción y la creación de instrumentos para contribuir al desarrollo educativo, económico y social del país, promoviendo el conocimiento científico. La Editorial forma parte del Departamento de Investigación Desarrollo e Innovación.

Tiene la misión de difundir los aportes de la academia en materia de ciencias, humanidades, tecnología y cultura. Está comprometida con el desarrollo académico y con los procesos informativos. Divulga los avances y retos que asume el la institución y promueve el acceso al conocimiento, proporcionando materiales editoriales que permiten la apertura de espacios de integración, discusión y creación académica entre los miembros de nuestra comunidad.

Para la comunidad académica es muy satisfactorio que nuestra editorial haga parte de las 28 editoriales que obtuvieron el Registro Definitivo correspondiente a la Convocatoria de Colciencias del 2012 y encontramos que este logro es un estímulo para la continuidad nuestra labor de estímulo a la creación de conocimiento científico y académico y a su difusión.

La Editorial del Politécnico Grancolombiano cuenta actualmente con cuatro revistas y con un importante número de publicaciones, que puede ser consultado en http://www.poligran.edu.co/editorial.

Sebastián Romero Buj

Director Revista Poliantea 